\title{
Evaluation of Level of Service in Rural Water Supply Schemes in Selected Southern Ethiopia
}

\author{
${ }^{1}$ Teketel Mirkeno \\ ${ }^{1}$ Lecturer, \\ Department of Hydraulic and Water Resources \\ Engineering, \\ Wolaita Sodo University, Ethiopia.
}

\author{
${ }^{2}$ Mesfin Meja \\ ${ }^{2}$ Lecturer, \\ Department of Hydraulic and Water Resources \\ Engineering, \\ Wolaita Sodo University, Ethiopia.
}

\author{
${ }^{3}$ Matusala Bassa \\ ${ }^{3}$ Lecturer, \\ Department of Civil Engineering, \\ Wolaita Sodo University, Ethiopia
}

\begin{abstract}
This study was conducted to evaluate the level of service in rural water supply schemes by using both qualitative and quantitative data gathering method. Questionnaire, focus group discussion and key informant interview, field observation, existing document reviewing are the major data gathering techniques used in this study. The numerical part of the data were analyzed using Microsoft excel, SPSS (Statistical package for social science) the result was represented through tables, graphs and charts and the word parts was digested in the narration form. The bacteriological water quality analysis in the sampled points has problems as compared with WHO drinking water standard and it is not recommended for drinking. Appropriate finance mechanisms of operation and maintenance when schemes fail by collection of daily water tariff and additional contribution of user communities to sustain the water supply projects. The institutional support after water supply projects developed was weak due to no meaningful training given WASHCOs members to make them responsible for operation or repair and maintenance of the water point no improve under staffing problem in the system. From the survey results of the respondents, most household were allowed averagely to fetch about 25 to 75 liters per a day of water from the source and quantity of water consumed in the district per person per day which is not meets the target of national plan of UAP (15 l/p/day)in 30 minute round trips. Therefore, the rehabilitation and implementation new schemes better to tackle rural water supply the problems.
\end{abstract}

Key words: Functionality, rural water supply, service and sustainability

\section{INTRODUCTION}

Access to clean water and sanitation is universal need and basic as well as human right. As a matter of fact, people around the globe face a problem of water scarcity. About $70 \%$ of the earth's surface is water and $3 \%$ of this is fresh water. Yet, out this, $99 \%$ is found beneath the surface. Surprisingly, most of this water is largely unavailable for utilization [1]. As stated in UNDP [2], currently 700 million people in 43 countries live with water scarcity of these many are in sub-Sahara Africa which represents one quarter of the global population that faces water scarcity live in developing countries. This scarcity of water forced people around the world to use unsafe water for drinking and other domestic uses [3].
As reported by [4] around 94\% of the global diarrheal burden and $10 \%$ of the total disease burden are due to inadequate sanitation and poor hygienic practices. On the other hand, Ethiopia has an estimated annual runoff 122 billionm $^{3}$ and 2.8 billionm $^{3}$ of ground water potential [5]. This corresponds to an average of $1,731 \mathrm{~m}^{3}$ of physically available water per person per year, a relatively large volume. However, due to large spatial and temporal variations in rain fall and lack of storage, water is often not available where and when needed [6], only about $3 \%$ of water resource are used of which only about $11 \%(0.3 \%$ of the total) is used for domestic water supply. Due to this the access to water supply and sanitation in Ethiopia is amongst the lowest in Sub-Sahara Africa and the entire world [7].

According to [5], the Millennium Development Goals (MDGs) of Ethiopia is expected to increase the improved water supply coverage from 2004 levels of $25 \%$ water supply and $8 \%$ sanitation to $62 \%$ for water supply and $54 \%$ sanitation by 2015 .

Therefore, realizing the critical importance of supplying portable water, national and regional governments, local and international NGOs invest many millions of capitals every year in developing countries to tackle the problem through the implementation of water supply projects. Thus, this study was intended to evaluate the levels of services of rural water supply projects in the study area. Moreover, the study was intended to assess factors that affect rural water supply schemes functionality and sustainability.

\section{MATERIALS AND METHODS}

\subsection{DESCRIPTION OF THE STUDY AREA}

A Kachabirra district is one of the districts in Kambata Tembaro zone in Southern Nation Nationalities and peoples region. The district capital is found $327 \mathrm{Kms}$ away from the capital, Addis Ababa and144 Kms away from the regional capital, Hawassa. The district lies between N07 $17^{\prime} 08.3^{\prime \prime}$ and E37 $47^{\prime} 04.8^{\prime \prime}$ North latitude and N07 $12^{\prime} 30.1^{\prime \prime}$ and E037 50 '30.6" degree east longitude [8]. The total area of the district is estimated to be 306 square kilo meters and is divided in to 20 rural and 2 semi urban kebeles. 


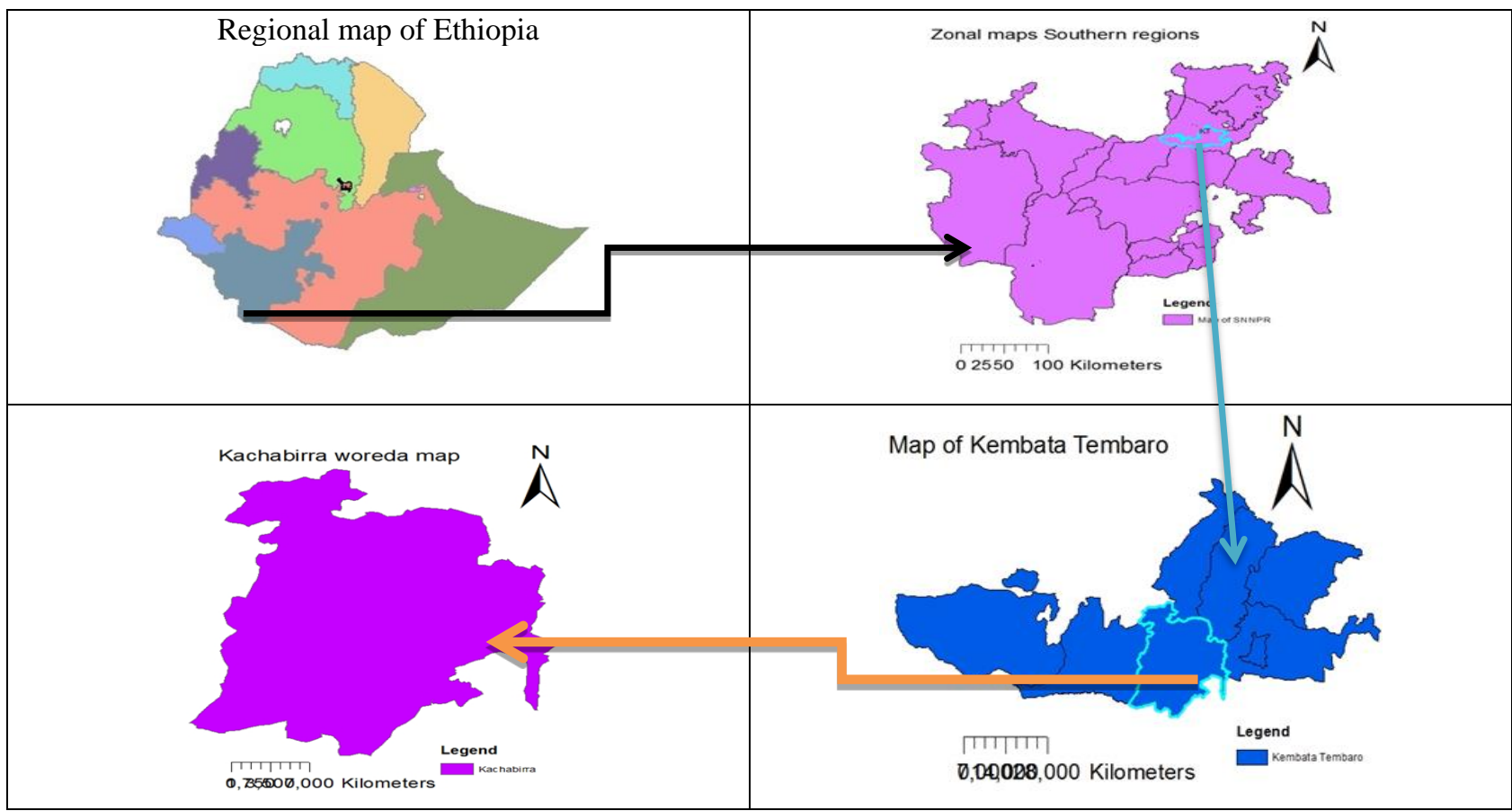

Figure 1: Location map of the study area

\subsection{METHODS OF DATA COLLECTION}

$>$ Primary data collection

- Household survey;

Information was collected from sampled households by using structured interview questionnaires.

- Focus group discussion;

Water user committee (WASHCOs) and community were interviewed.

Key informant interview

NGOs and district water resource development department.

- Field observation; Current states of water supply schemes, design system, Carrying capacity (actual) and damage conditions and its causes, sanitary issues and relevant data's were observed.

$>$ Secondary data collection

Reviewing of existing different data sources publications, research documents and reports and other sources from sector offices and concerned bureaus inside and outside of the district were carried out..

\subsubsection{SAMPLE SIZE AND TECHNIQUE}

- Sampling size:

Representative random sampling was employed and determined by setting confidence interval of $95 \%$ and margin of error 5\% using the following formula.

$\mathrm{SS}=\frac{\mathrm{P}(1-\mathrm{P}) \mathrm{Z}^{2}}{\mathrm{C}^{2}}=\frac{3.8416 \mathrm{x} \cdot 5 \mathrm{x} .5}{0.0016}=600$

$\mathrm{SS}=$ Sample Size.

$\mathrm{Z}=\mathrm{Z}$-value (1.96 for a 95 percent confidence level).

$\mathrm{P}=$ Percentage of population picking a choice, expressed as decimal (0.5).

$\mathrm{C}=$ Confidence interval, expressed as decimal (0.04).

Sample size: finite population (Where the population is less than 50,000).

New $S S=\frac{S S}{[1+(S S-1 / P O P)]}=\frac{600}{[1+(600-1 / 2890)]}=500 \mathrm{HHs}$
Pop $=$ Population

Therefore, by the representative sampling method 500 households were selected for the interviews.

$\checkmark$ Sampling technique:

The first users were taken by lottery method at every $6^{\text {th }}$ interval individual household was interviewed by using the following formula.

Interval of households $=\frac{\text { Total number of household }}{\text { ss }}=2890 / 500$ $=5.78 \sim 6$ (interval households for interview).

\subsubsection{STUDY INPUT VARIABLES}

The study variables assessed in this research are both independent and dependent variables.

- Independent variable: are more related with specific objectives.

$\checkmark$ Design

$\checkmark$ Operation

$\checkmark$ Structural quality

$\checkmark$ Functionality of schemes

- Dependent variable: variables which are the output and its result depend on the independent variables which related to general objective.

$\checkmark$ Service of water

\section{RESULT AND DISCUSSION}

\subsection{GENERAL BACK GROUND INFORMATION OF THE RESPONDENTS}

This section was concerned about the back ground information of the respondents. It delivers a general over view of water uses, collections and allocations in rural household in the study area. The common identified back grounds are; Sex, education, occupation and household size of the respondents. These highly determine the water 
demand in the households and the extent to which the house holds get involved in this subject. These can help researcher to see which areas are critical to enhance rural water supply systems.

Table 1: General back ground information about the respondents

\begin{tabular}{|c|c|c|c|}
\hline General back ground respondents & Constraints of respondents & Frequency & Percent \\
\hline \multirow[t]{3}{*}{ Sex } & Male & 219 & 43.8 \\
\hline & Female & 281 & 56.2 \\
\hline & Total & 500 & 100 \\
\hline \multirow{6}{*}{ Educational status } & Illiterate & 241 & 48.2 \\
\hline & first cycle & 144 & 28.8 \\
\hline & second cycle & 77 & 15.4 \\
\hline & high school & 27 & 5.4 \\
\hline & above high school level & 11 & 2.2 \\
\hline & Total & 500 & 100.0 \\
\hline \multirow[t]{5}{*}{ Occupation (income source) } & Farming & 407 & 81.4 \\
\hline & Employee & 35 & 7 \\
\hline & daily labour & 40 & 8.0 \\
\hline & small scale business & 18 & 3.6 \\
\hline & Total & 500 & 100.0 \\
\hline \multirow[t]{4}{*}{ Family size } & $1-4$ & 141 & 28.2 \\
\hline & $5-6$ & 261 & 52.2 \\
\hline & $>6$ & 98 & 19.4 \\
\hline & Total & 500 & 100.0 \\
\hline
\end{tabular}

From table 1 the sample respondents' high percentage $(56.2 \%)$ is female and the remaining $43.8 \%$ is male. From this women are dynamic participant in socio economic issues; they are responsible for fetching, collection, usage and provision of water supply. Because of this, participation of women is crucial as it could render the real problems and proposed solution regarding water issues.

Educational level (status) of the respondents given in table 4.1 in the study area majority, $48.2 \%$ of the respondents were illiterate. About $28.8 \%$ of the respondents have first cycle, $15.4 \%$ second cycle, $5.4 \%$ high school level and $2.2 \%$ above high school level. Therefore, most percentages of respondents are uneducated due to this reasons there is limited awareness water supply system and management. From the same table also the sample households have different occupation. These include farm, employee, small scale business and daily labour including additional income of households. From total of 500 sample household $81.4 \%$ farmers, $7 \%$ employee, $8 \%$ daily labour and $3.6 \%$ small scale business. Mixed farm is common source income in the area. Family sizes of the households are main factor to determine the amount of the water available and to construct as well as develop water points. From the survey result $28.2 \%$ are between $1-4$ family members, $52.2 \%$ are 56 family members and $>6$ family members are $19.6 \%$.

\subsection{SOURCE OF WATER SUPPLY}

The main source of the water supply in the study area is spring, hand dug wells and shallow wells. Among these springs are dominant and high percentages of the water supply source in the district covers $53.2 \%$. Others hand dug wells and shallow wells covers $25.8 \%$ and $21 \%$ respectively.

Table 2: Source of rural water supply

\begin{tabular}{|l|c|c|}
\hline \multicolumn{2}{|c|}{ Table 2: Source of rural water supply } \\
\hline Hand dug wells & Frequency & Percent \\
\hline Springs & 129 & 25.8 \\
\hline Shallow wells & 266 & 53.2 \\
\hline
\end{tabular}

\subsection{SPATIAL DISTRIBUTION OF WATER SUPPLY SCHEMES}

As represented below in sampled districts water supply schemes or points in the map shows the coverage of water points with in the $1.5 \mathrm{~km}$ radius in sampled kebele above $73 \%$ coverage with in these rounds. This contains both functional and non-functional water supply schemes shown in the map. Therefore, such estimation is important for the foregoing deductions.

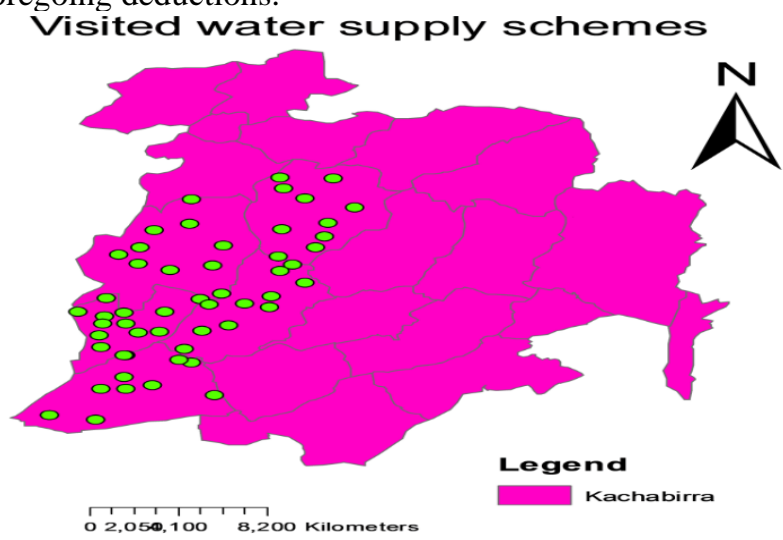

Figure 2: Distribution of visited water points in the district

\subsection{DOMESTIC WATER USES AND ITS SERVICES LEVEL INDICATORS}

Domestic water use patterns are normally similar in the study area regardless of the types of the water supply schemes and the distance covered to reach the water point.

\subsubsection{AMOUNT OF WATER COLLECTION AND HOUSEHOLD WATER USES}

The average amount of water collection per day depends upon different factors of water supply systems that mean availability of water, ground water levels, population, household size and number in the community. From the survey results of the respondents, most household were 
allowed to fetch about 25 to 75 liters per a day (by 25 or 10 liters jarycans) of water from the source.

Multiple use water supply services are intended to meet the domestic and productive demand of the poor in more comprehensive manner. If appropriately planned, designed and managed, they have a much greater potential to reduce poverty to lesson health hazards and to circumvent livelihood vulnerability of rural households. They can also facilitate gender equity, cost recovery and sustainability of the water facilities [4].

From the survey results the main uses water in the households is for domestic purposes $100 \%$. All sampled households uses jarycans to collect water, these jarycans which can holds 25 liters and children use 10 liter jarycans. The per capital consumption of water in each respondent household was calculated by: Multiplying the number of jarycans use per day with the average amount of liters it contains then dividing the results by average household family members. Therefore, the daily personal consumption minimum 15 liter per person per a day and yearly consumes 5475 liters per year MDGs target but only $14 \%$ of respondents meet this target in the districts means that 15 1/p/day shown figure below.

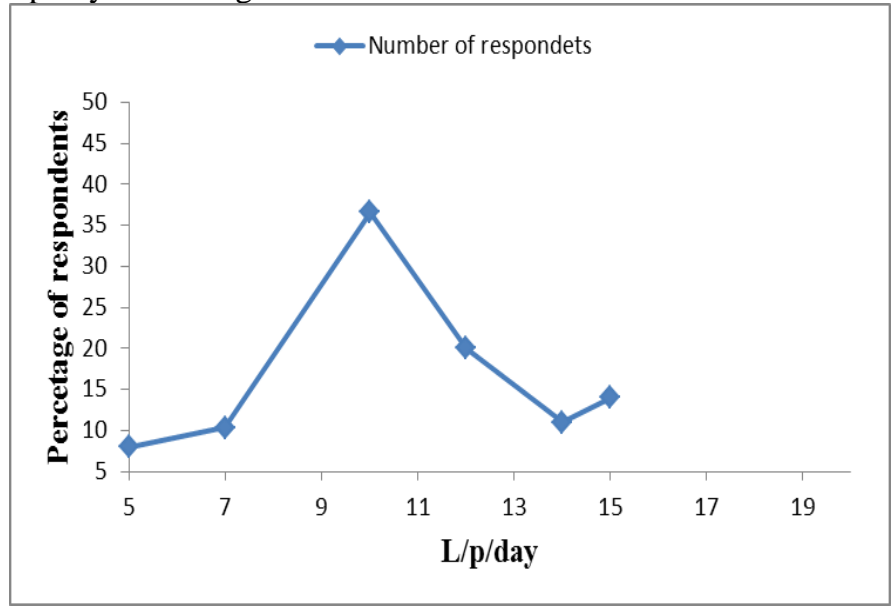

Figure 3: Average water consumption of respondents' liter per person per a day

\subsubsection{ACCESSIBILITY OF WATER SUPPLY \\ SERVICES}

I. The distance travelled and time required fetch water

According to [5] indicates that women in rural areas often travel long distance to collect water accounting for to two to six hours per day. The respondent in the study area were asked to give information on the time it took them to fetch water from water supply schemes. Although the values obtained were not based on exact measurement it is approximately used to estimate the time taken from rural water supply services. The researcher was so careful about over estimation and under estimation. UAP aims 30 minute round trips time to collect water from source for rural supply systems. From the survey results the maximum time to fetch water from the supplied services including waiting time varies from 15 minutes to 150 minutes with mean duration 63.45 minutes and standard deviation of above 31.65 minute. Above $15 \%$ of the respondents of households meet the targets set for time spent to fetch water in 30 minute round trips of [7]. From the field observation the increasing time to collect water is directly related line waiting.

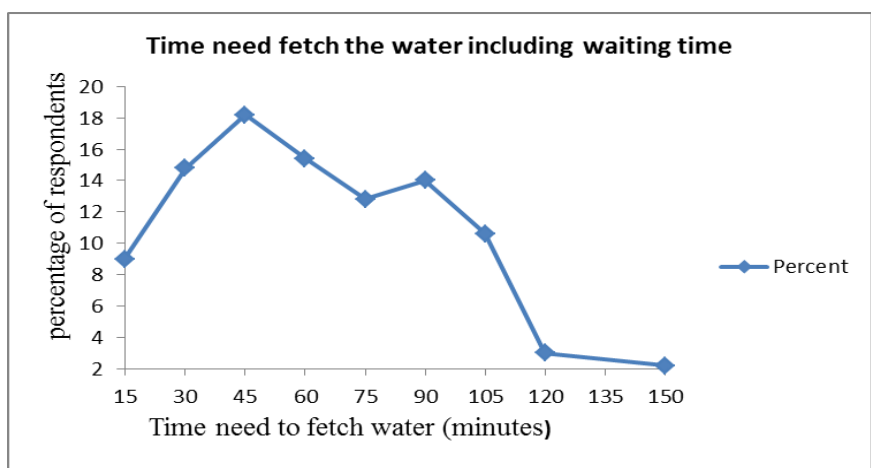

Figure 3: Time need to fetch water from the source including waiting time

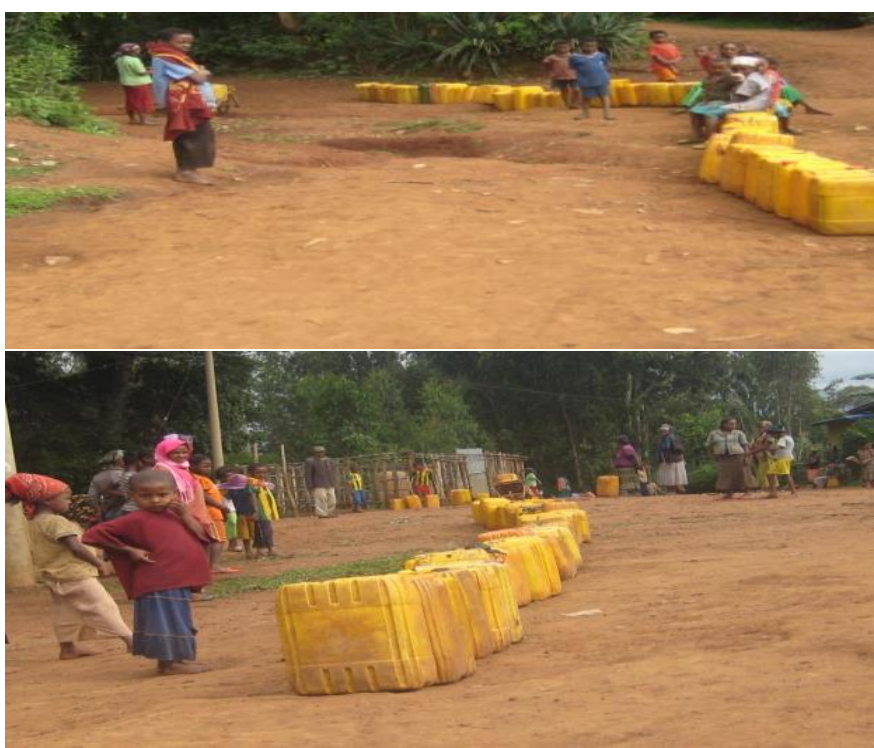

Figure 4: Longest waiting line observed at water point in Gemesha kebele

\subsubsection{RELIABILITY OF WATER SUPPLY SERVICES}

The matters functionality of water supply systems and periodical variation is an area that needs to be given greater attention. It is measured by interruption and water shortage.

\section{Service interruption}

About $61.6 \%$ of sampled respondents replied service interruption by system failure and $38.4 \%$ is due to drying of water source. The minimum and maximum periods of interruption from three up to four months (13\%) and two up to three months (26\%),respectively. 
Table 3: Service interruption

\begin{tabular}{|c|c|c|c|}
\hline constraints & Choice & Frequency & Percent \\
\hline \multirow[t]{2}{*}{ Service interruption from the water point } & Yes & 185 & 37 \\
\hline & No & 315 & 63 \\
\hline \multirow{5}{*}{$\begin{array}{l}\text { periods of Service interruption } \\
\text { in a year }\end{array}$} & one months & 46 & 24.9 \\
\hline & one up to two months & 33 & 17.8 \\
\hline & two up to three months & 48 & 26 \\
\hline & three up to four months & 24 & 13 \\
\hline & above four months & 34 & 18.3 \\
\hline \multirow[t]{3}{*}{ Reason of service interruption } & System failure & 114 & 61.6 \\
\hline & Drying of source & 71 & 38.4 \\
\hline & Others & 0 & 0 \\
\hline
\end{tabular}

\section{Water shortage.}

The water supply schemes driest periods (HDWs and Shallow wells) from January to March their discharge rate is reduced due to ground water table reduced. In this period, users face problems such as shortage of water for domestic purpose and other uses and travel long distance to collect water from another source.

\subsection{Factors affecting efficiency of water supply projects (sustainability)}

The determinants of sustainability are:

$>$ Suitability of selected sites

$>$ Quality of constructed facility

$>$ Suitability of implemented technologies,

$>$ Protections of schemes after implementation.

\subsubsection{Suitability of selected sites}

Correct site selection is important to efficient uses of resources, time and money to safeguard sustainability of the projects.

I. Technical

The technical criteria fulfill the following ideas such as measured discharge from the water source; distance from the contaminants would reflect selection of site for water supply schemes. Since insufficient quantity of water for the targeted beneficiaries, nearer to cultivation land, residents (home) and latrines from the water sources are concerns of poor site selection which can negatively affect sustainability of water supply schemes or target of the projects.

From field visited on averagely $32 \%$ schemes constructed (implemented) sites are not in suitable site in the district because there location is very near to agricultural field, residents' areas with contamination with latrine risks from homes flow.

Therefore, the main causes of the problems observed and discussion with WASHCOMs are;

$>$ Shortage of sufficient technical inputs from the experts (Either water engineer or geologist).

$>$ Sometimes construction facilities at the construction time.

\section{Social (acceptance in a community)}

From the field visited, focus group discussion and survey of the respondents some of the beneficiaries raises problems related to social aspects such as various thinking on WASHCOs members elected by local leaders, no auditing of fee collected, some water points massive users and long waiting to collect water, long distance walk above $1.5 \mathrm{~km}$ round and not get adequate water and also between them conflicts.

II. Environmental factors

The environmental problems have been seen during field observation time study were

$>$ Soil erosion (degradation of water shed)

$>$ Drainage issues nearby water points

$>$ Pollution around the HDWs which are favorable area for the breeding place of the mosquitoes and ultimately water-borne diseases.

From the observation and discussion with WASHCOs the condition and existence of drainage facility half percent sampled schemes don't have drainage problems and other percentages are under the condition of drainage problems. 


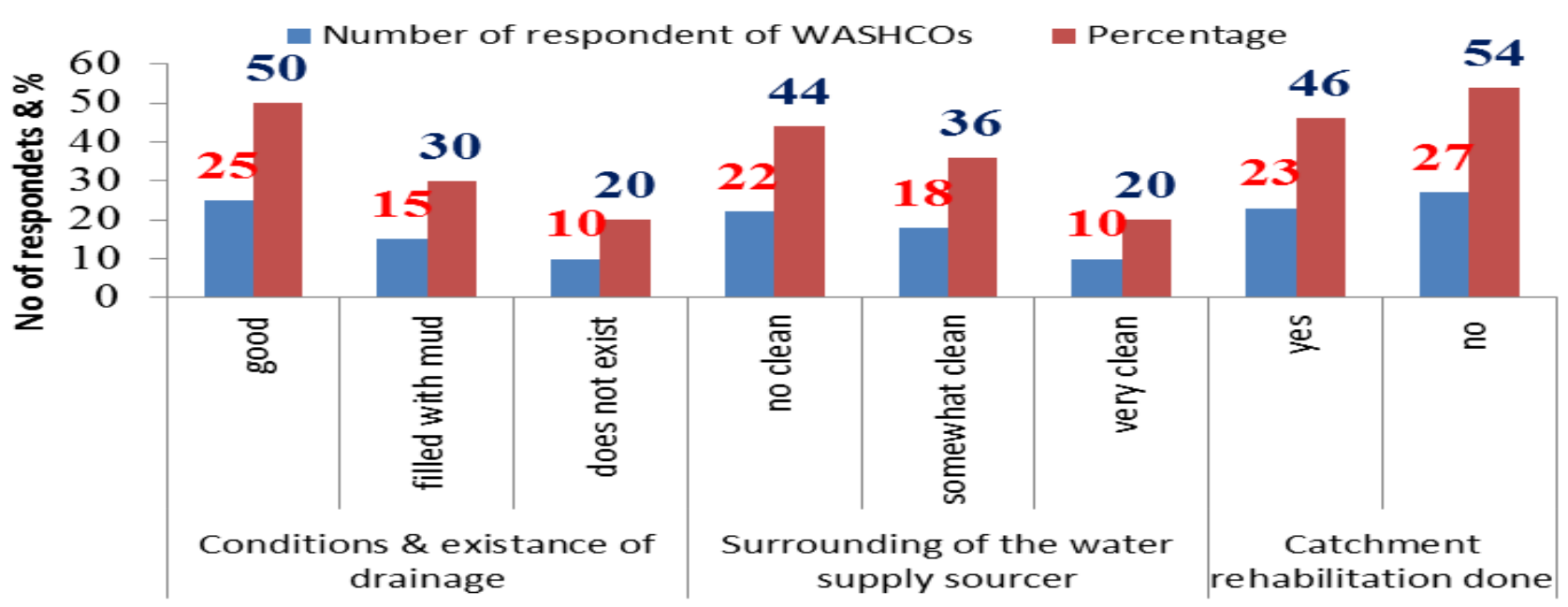

Conditions of environment of the schemes

Figure 5: Environmental problems of rural water supply scheme

\subsubsection{SUITABILITY OF TECHNOLOGIES}

Proper technology selection is important for sustainability of rural water supply schemes. These technologies are chosen based on spare parts availabilities, cost and capacity for operation and maintenance in the community.

From field visited and key informant discussions most of the technologies in the district area are Indian mark types which much expensive than as compared to Afridev marks based on their spare parts cost.

I. Spare parts availability

From focus group discussion (WASHCOs) and respondents mentioned spare parts supply were main problem to provide maintenance.

These tools are not available to the community up to now in the district. From field visit and explanation from WASHCOs that transportation cost and time required buying spare parts is causing difficulty to do instantaneous maintenance when schemes fail. Therefore, no spare parts distributor is available in the district.

II. Availability of local skills (technicians) for maintenance Chosen technologies should fit to locally available skilled man power for maintenance because community will be responsible for running the facilities.

From the field visited schemes (HDWs) and some shallow wells were fitted with hand pumps. But in the kebele level technicians have not yet developed skills for maintenance of pumps. In the study districts the pump maintenance totally dependent on one technician or expert from district office and the others trained from the community were not skillful.

\subsubsection{QUALITY OF CONSTRUCTION ON THE DEVELOPED SCHEMES}

Construction quality is one of the most important factors for functionality of water supply schemes and further useful for the future sustainability of the schemes.

From survey results, focus group and key informant discussions the construction is poor or not practical: due to without necessary construction materials and design problems, in adequate supervision during the implementation periods, absence of the administrative role in monitoring and evaluation during of schemes construction.

From this $56 \%$ of the observed water points were constructed with good quality and rest $44 \%$ within poor quality were affected by poor construction.

schemes construction quality in the feild observed

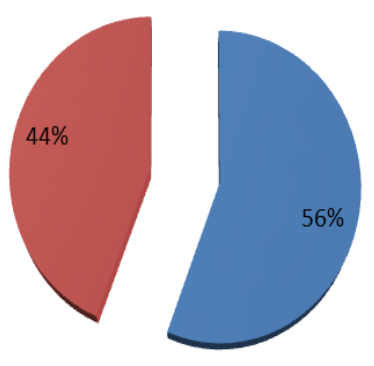

good

apoor

Figure6: Schemes construction quality observed

\subsubsection{PROTECTION AFTER IMPLEMENTATION OF WATER SUPPLY SCHEMES}

Protection of water supply schemes after implementation is important factor for the functionality and sustainability of the rural water supply schemes.

From the field observation results, $60 \%$ schemes have guard and $40 \%$ have no guards, because of the most of WASHCOs not awarded to pay this work.

In addition to $54 \%$ of visited schemes not properly fenced and only $46 \%$ fenced, similarly visited water points ditches were filled with dirt and not draining water effectively and $16 \%$ swampy problem around the water point (breeding sites for mosquitoes which causes malaria on the community).Therefore, the protection of schemes by guards, fencing is primary stage to keep the source from misuse and damages. 


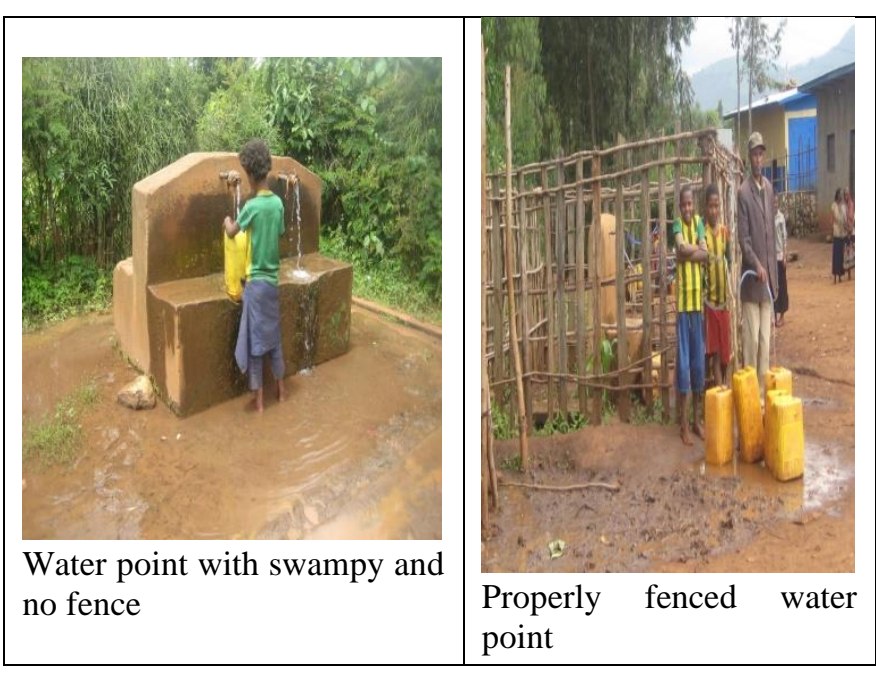

Figure 7: Stages of water points after construction.

\section{CONCLUSION AND RECOMMENDATION}

\subsection{CONCLUSION}

Water supply adequate in quantity and accessibility is the basic need of human being. The problems in rural areas of developing countries are particular concern as still large sections of the community are living without safe water services. The state of water supply in terms of coverage in spatial and for population accessibility is not required standard. To solve such problems Ethiopian government set the goal and target on its Millennium Development Goals. However, it is still lacking far behind the target.

From the results of the study as assessed only $14 \%$ of respondent's meets water usage of the target of UAP of 15 $1 / \mathrm{p} / \mathrm{d}$. From the data indicated that most of the community in $1.5 \mathrm{~km}$ distance not get targeted UAP amount of the water. In the district water point's location above $73 \%$ of the total area of the covered in $1.5 \mathrm{~km}$ distance which is concerned efforts to meet Millennium Development Goal of water and sanitation for all by 2015 but this is only construction coverage. The most of the rural water supply schemes in the study area were constructed by NGOs, which were mainly focused on construction of new schemes. Only little provision was made for operation and maintenance of the constructed water supply schemes. This shows that maintenance of the schemes was neglected aspect of rural water supply schemes. The existing water supply schemes in the district were characterized by low service coverage and poor operation \& maintenance as only $64 \%$ of the observed schemes the fully functional and supply's water to the community. The left $36 \%$ of the schemes were nonfunctional due to design, environmental, technical, availability spare parts, operation \& maintenance and construction problems.

Appropriate finance for the operation and maintenance of water supply schemes by water tariff collection and additional contribution of the community and it is inefficient. Finally, institutional support is especially in necessary to beneficiaries' capacity building on operation and maintenance of schemes and little rehabilitation cost contribution. But more capacity building training is essential to increase capacity of WASHCOs and technicians of the community on the base of operation and maintenance and Managements of schemes.

\subsection{Recommendations}

The following recommendation is be useful in achieving more effective and efficient provision of water supply in the study district.

$>$ Take priorities to damaged water supply projects rehabilitation; it saves time, money and resources.

$>$ Chlorinating, boiling and filtering those sources before consumption purpose use.

$>$ Effective capacity building training give to WASHCOs on concept of schemes management, operation \&maintenance, fee collection ways from the users, management of sanitation problems and community participations.

$>$ The implementation agencies mainly took attention on sustainability of water supply projects by creating spare parts availability for the maintenance with involvement of private sectors.

$>$ Watershed protection or schemes catchment protection by reforestation, land degradation (erosion and flooding) protection. It is useful to increase the ground water recharge.

$>$ Government and non-government organization (NGOs) focuses on the improving coverage water supply. But due attention is necessary to address the problems that recover the sustainability, such as introducing new and modifying previous technologies.

\section{BIBLIOGRAPHY}

[1] Duddin, $\mathrm{K}$ and Hendrie, A, in World Land and Water Resource, Ho and Stoughton, London., 1988.

[2] U. N. D. P. (UNDP), " Millennium Development Goal report," 2008.

[3] WHO,"http://www.who.int/features/factfiles/water/waterfacts/en/in dex3.html," 2009. [Online]. [Accessed 20 october 2013].

[4] Fewtrell, "Water, sanitation and hygiene: quantifying the impact at national and local levels in countries with incomplete water supply and sanitation coverage," WHO. Geneva., 2007.

[5] A. D. Fund, "Rural water supply and sanitation program appraisal report," Infrastructure department, North, East and South, ONIN, ADF, 2005.

[6] Seleshi, "Internatonal Water Management Institute: water and Irrigation Development in Ethiopia," 2007.

[7] M. o. W. Resource, "Water supply and sanitation in Ethiopia," encyclopedia, pp. 10-50, 10 August 2012

[8] K. T. z. e. mines, "KTZWIEOR," 2014.

[9] WHO,"http://www.who.int/features/factfiles/water/waterfacts/en/in dex3.html," [Online]. [Accessed Accessed 20 Accessed October 2013]. 